\title{
Using the Competing Value Framework Model for Developing an Organizational Culture Profile in Governmental Hospitals
}

\author{
Sabah Mahmoud Mahran \\ Nursing Administration Department, Faculty of Nursing, Port Said University, Port Said City, Egypt
}

Email address:

dr.sabahmahran@yahoo.com

\section{To cite this article:}

Sabah Mahmoud Mahran. Using the Competing Value Framework Model for Developing an Organizational Culture Profile in Governmental Hospitals. American Journal of Nursing Science. Vol. 5, No. 6, 2016, pp. 288-294. doi: 10.11648/j.ajns.20160506.18

Received: December 19, 2016; Accepted: December 27, 2016; Published: January 18, 2017

\begin{abstract}
An organizational culture has been studied over the decades to be understandable. This research aimed to find out the most dominant culture profile for each hospital by using the competing value framework (CVF). Quantitative descriptive and analytical design were applied to find out the organizational culture profile. Two hospitals were selected to represent the governmental hospitals in Port-Said city. Total studied sample 250 participants. A convenience sample was implemented. Generally, the highest mean score of an agreement was $(\mathrm{M}=3.3$, at $\mathrm{SD}=0,74)$ reported for the Hierarchy organizational culture followed by Clan culture at $(\mathrm{M}=3.29 \mathrm{SD}=.75)$. While the lowest mean score for agreement was $(\mathrm{M}=3.2, \mathrm{SD}=0.70)(\mathrm{M}=3.2$, $\mathrm{SD}=0.72$ ) for the Adhocracy and Market organizational culture. The findings of this study indicated that the organizational culture type and culture profile for each hospital. This study recommended that the managers have to permits of an expressing the ideas of empowering and encouraging the care providers to participate in decision-making and problem-solving process and conduct training workshop to learn and improve the organizational culture in a manner that will increase the chances of financial and operational success.
\end{abstract}

Keywords: Organizational Culture, Culture Profile, Competing Value Framework (CVF)

\section{Introduction}

An organizational culture is considered as characteristic, internal variable, and unique feature of every organization. There is also agreement believes that strong culture facilitates coordination and communication in comparing with other organization and determine successful from an unsuccessful organization (Mitrovic et al. 2014). Generally, people do not recognize their own culture until they expose to other culture or are faced some changes to their own. First, organizational culture study has appeared in the management science around the end of the twentieth century when the Japanese companies adjust the drivers' environmental change which directs the attention of scholar to study the organizational culture (Balogh, Gaal, \& Szabo, 2011). The Scholar debate focused on whether culture should be viewed from perspective of materialist or ideational and construct of unitary or distribution and how it should be studied and assessed ( Alizadeh \& Panahi, 2013).
In the Middle East, a study was done in Saudi Arabia, it was aimed to examine the impact of an organizational culture on an employee performance. This research was studied by Awadh, \& Saad (2013) mentioned that some of the dimensions of an organizational culture created a significant influence on the organizational performances as power distance, individualism, uncertainty avoidance and masculinity. In fact, the organizational culture has helped in measuring the limitations to overcome the measurement of the performance. There is a negative correlation occurred between the culture and the performance of an employee. An organizational culture in the health care has a significant role in creating quality healthcare and provide safety for the patients. An employee with good values will naturally exhibit working behavior leading to a quality healthcare system (Domnaria,2013). An additionally, a safety culture is similar to the organizational culture in the medical field, which refers to the safety of clients. King \& Byers (2007) noted that safety and quality of patient care are influenced by the outcomes of research and evidence-based 
practice that use the organizational culture determinant where the organizational culture draw up the healthcare professionals implicitly and shape their work action and pattern. In an Egypt, one study was conducted to investigate the impact of hospital organizational culture on patient safety management from the perspective of nurses and physicians. It is concluded that overall, developmental culture and group (team -work) culture were found to have significant positive correlations with patient safety management and therefore they are better aligned with patient safety management. While both rational and hierarchical cultures were found to have significant negative correlations with patient safety management and they are less favorable to patient safety management (Seada, 2012).

Culture is defined as gained knowledge, value, beliefs, explanation, behavioral, communication of group of people at the same time and the same place (Shahzad, 2012).

An organizational culture reflected a set of specific behaviors, rules or norms, which members believe they should adopt to continue and work within an organization. These behavioral patterns may be productive or not and can lead to behaviors and attitudes that determine how the members approach their work and interact with each other (Daft and Marcic,2009). Moreover, the organizational culture displaying characteristics of accountability, collaboration, decentralized leadership, alignment and adaptability hold the key to successful persistence. Additionally, it considered as the most powerful and stable forces operating within an organizational environment. Furthermore, direction, pervasiveness and strength are the three interrelated aspects used to examine the impact of organizational culture on an organizational effectiveness (Sanjeevl \& Aditi, 2010).

An Organizational Culture Assessment Instrument (OCAI) is a research tool developed by Cameron and Quinn (2011) based on the CVF. It has a set of four statements within six main items used to extract employees' opinions based on their experiences. These are: Clan culture (internal focus and flexible) friendly workplace where leaders act like father figures. Adhocracy culture (external focus and flexible) A dynamic workplace with leaders that stimulate innovation Market culture (external focus and controlled) competitive workplace with leaders like hard drivers. Hierarchy culture (internal focus and controlled) A structured and formalized workplace where managers act like coordinators. Morover, Yu. (2009) mentioned that CVF and matched scales Organizational Culture Assessment Instrument (OCAI) have the better validity and reliability compared with other models and scale in the context of China.

Aim of the research

To find out the most dominante culture profile for each hospital by using the competing value framework (CVF) through;

1 Identify dominant culture type in both current governmental hospitals.

2 Clarify the strength of the culture type.

3 Formulate the culture profile findings among careproviders at both hospitals.

\section{Research Methodology}

\subsection{Research Design}

Quantitative descriptive and analytical design were used to find out the organizational culture type by using the competing value framework (CVF) used as the model for the study.

\subsection{Setting}

Two hospitals were selected to represent the governmental hospitals in Port-Said city, these hospitals are Port Said General Hospital and El-Nasser. They are the biggest hospitals affiliated to Ministry of Health in Port-Said City.

\subsection{Population}

This study targeted the hospitals careproviders (Doctors, Pharmacists, and all levels of Nurses). The studied sample included the careproviders who are working in the selected setting both male and female. The included subjects have to work for more than one year in the hospitals. Convenience sample were selected. Where the sample size calculated online (http://www.raosoft.com/samplesize.html) with accordance of $5 \%$ of margin error, confident level of $95 \%$, and the sample size was 250 participants.

\subsection{Data Collection Tool}

An Organizational Culture Assessment Instrument (OCAI) was used for measuring four types of organizational culture (Clan, Adhocracy, Market \& Hierarchy culture). It is devided into two parts. The first part is developed by the researcher. This part consistes of questions related to sociodemographic data to collect general information's about studied sample as; gender; level of education; level of experience-etc. The second part is adopted from Aldhuwaihi (2013). It consists of six dimensions, each dimension has four statements. The dimensions are: 1- Dominant characteristics, 2organizational leadership, 3- management of employees, 4hospital glue, 5- strategic emphases, and 6- criteria of success. The OCAI adopted five-point Likert scale ranged from 1: strongly disagree to 5: strongly agree. which is distribution of the score over the variable that equal to constant. The questionnaire was translated into Arabic language. One expert in English language reviewed the translation and the modifications were done.

\subsection{Pilot Study}

The pilot study was conducted to test the instrument applicability in different setting and culture. The studied sample was taken randomly as $10 \%$ from the total sample which is equal to about 30 questionnaires distributed randomly over the hospital care providers. The piloting studied subjects were excluded from total studied sample.

\subsection{Validity and Reliability of Instrument}

The researcher used an organizational culture assessment 
instrument (OCAI), it consists of six dimensions, each dimension has four statements. The instrument is revealed significant result and high reliability of internal consistency (Cronbach- alpha), Clan culture $=0.818$, Adhocracy culture $=0.847$, Market culture $=0.860$, and Hierarchical culture $=$ 0.905 . The content validity of tool was done by the penal of experts who are a professor in nursing administration for testing the content clarity, sentences understanding \& the time required filling up the tool.

\subsection{Procedures}

After obtained permission from the hospital directors and nursing administration, the researcher presented all required information to the participated care providers. The studied sample was selected based on their schedule which includes their names from each hospital. The data was collected on three days each week for one month start from 20th July up to 20 August 2016. The care providers were given the selfadministered written the questionnaire and asked them to fill it. Each questionnaire was required 15-20 minutes to be answered, so, the researcher was collecting back the questionnaire from the care providers.

\subsection{Ethical Consideration}

An official permision was obtained from the hospital directors to start the data collection and oral consents were obtained from the studied subjects as well as explain the aim of the study to each participant to be familiar with the importance of their participation and a brief explanation of the purpose and importance of the study was given to the careproviders.

\subsection{Data Analysis}

An analysis of data was done by the SPSS version 22. The main concern is to find the mean and standard deviation of each type of the culture and developing the graphs of each dimension in an organizational culture assessment instrument that was used in an organizational culture profile of each hospital. Each hospital data was calculated separately to develop the profile, where the governmental hospital's culture was generalized by the result of both hospitals.

\section{Results}

The total studied sample size was 250 care providers, 150 from Port Said General Hospital and 100 from El-Nasser hospitals. The frequencies and percentages of sociodemographic data of studied sample was presented in table 1 . Most of the studied sample (73.6\%) was female, their age ranged from 30 to 39 years old $(n=100,40 \%)$. While $60 \%$ of them were married. Slightly above half percent $(52 \%)$ had a Diploma in nursing followed by the Bachelor degree $(36 \%)$ than a Master's Degree $(8 \%)$. While only 10 had Doctorate degree. About $40 \%$ of studied sample had 1-5 years experience.
Table 1. The frequencies and percentages of sociodemographic data of total studied sample $(n=250)$.

\begin{tabular}{|c|c|c|c|}
\hline & & Percent $\mathrm{N}=\mathbf{2 5 0}$ & Frequency $N=250$ \\
\hline \multirow{2}{*}{ Gender } & Male & 66 & $26.4 \%$ \\
\hline & Female & 184 & $73.6 \%$ \\
\hline \multirow{4}{*}{ Marital status } & Married & 150 & $60 \%$ \\
\hline & Unmarried & 82 & $32.8 \%$ \\
\hline & Divorced & 10 & $4 \%$ \\
\hline & Widow/er & 8 & $3.2 \%$ \\
\hline \multirow{5}{*}{ Age } & $20-29$ & 90 & $36 \%$ \\
\hline & $30-39$ & 100 & $40 \%$ \\
\hline & $40-49$ & 36 & $14.4 \%$ \\
\hline & $50-59$ & 16 & $6.4 \%$ \\
\hline & $>60$ & 8 & $3.2 \%$ \\
\hline \multirow{4}{*}{ Education level } & Diploma & 130 & $52 \%$ \\
\hline & Bachelor & 90 & $36 \%$ \\
\hline & Master & 20 & $8 \%$ \\
\hline & $\mathrm{PhD}$ & 10 & $4 \%$ \\
\hline \multirow{3}{*}{ Profession } & Physician & 50 & $20 \%$ \\
\hline & Pharmacist & 20 & $8 \%$ \\
\hline & Nursing & 180 & $72 \%$ \\
\hline \multirow{4}{*}{$\begin{array}{l}\text { Years of } \\
\text { experience }\end{array}$} & $<1-5$ & 100 & $40 \%$ \\
\hline & $5-10$ & 90 & $36 \%$ \\
\hline & $10-15$ & 30 & $12 \%$ \\
\hline & $>15$ & 30 & $12 \%$ \\
\hline
\end{tabular}

Table 2 displayed the summary of mean scores and standard deviations (SD) for organizational culture types which have been presented ranking by care providers respondents in both hospitals at $(\mathrm{M}=3.3, \mathrm{SD}=0,74)$ for the Hierarchy organizational culture followed by Clan at $(\mathrm{M}=$ $3.29 \mathrm{SD}=.75)$. In contrast, the lowest mean agreement is $(\mathrm{M}=$ $3.2, \mathrm{SD}=0.70)(\mathrm{M}=3.2, \mathrm{SD}=0.72)$ for the Adhocracy and Market organizational cultures.

Table 2. Summarized the mean score and standard deviations (SD) for organizational culture types in both studied setting as perceived by the care providers $(n=250)$.

\begin{tabular}{llc}
\hline Competing value framework $(\mathbf{C V F})$ & \multicolumn{2}{l}{ Studied } \\
& MEAitals $(\mathbf{N}=\mathbf{2 5 0})$ \\
\hline CLAN & 3.2962 & SD \\
ADHOC & 3.2410 & .75719 \\
MARKET & 3.2453 & .72954 \\
HIRARCH & 3.3142 & .74132 \\
\hline
\end{tabular}

Table 3 summarized six dimensions which were analyzed by the organizational culture assessment instrument by using the competing values framework. The highest mean score for the culture type in both currently studied hospitals. The highest mean score presented by care providers was for an organizational glue at mean $=3.4748$ followed by criteria for success at mean $=3.3966$; management of employees at mean $=3.3529$; strategic emphasis at mean $=3.1441$ and dominant organizational characteristics at mean $=3.0630$. 
Table 3. Mean score for six an organizational dimensions and Competing value framework (CVF) as perceived by studied sample ( $n=250)$.

\begin{tabular}{lllll}
\hline & Organizational diminsions & Mean & SD & Competing value framework (CVF) \\
\hline 1 & Dominant organizational characteristics & 3.338 & .72954 & Market \\
2 & Leadership style & 3.3489 & .74132 & Hierarchy \\
3 & Management of employees & 3.3529 & .75719 & Clan \\
4 & Organizational glue & 3.5738 & .74132 & Hierarchy\& \\
5 & Strategic emphasis & 3.2415 & .74132 & Hierarchy \\
6 & Criteria for success & 3.3966 & .75719 & Clan \\
\hline
\end{tabular}

Table 4 summarized the ranking of the total mean score for organizational culture types as perceived by studied sample in Port Said General Hospital and El-Nasser Hospital $(n=250)$. In Port Said General Hospital, the care providers ranked Clan was first culture type in their hospital at (mean=3.3246, $\mathrm{SD}=.85052$ ), followed by Hierarchy culture at (mean=3.2979, $\mathrm{SD}=.80369)$; Market at (mean= 3.2512, $\mathrm{SD}=.77468$ ). While the lowest mean score was for an
Adhocracy at (mean=3.2090, $\mathrm{SD}=.77024)$. On the other hand, in El-Nasser Hospital, studied sample was ranking Clan culture as the first choice for them at (mean $=3.5977$, $\mathrm{SD}=1.46356)$; followed by Hierarchy culture at (mean=3.5977, $\mathrm{SD}=.1 .29544)$; Market at (mean= 3.4742, $\mathrm{SD}=1.39034)$ and the lowest mean score was for Adhocracy at (mean=3.3991, $\mathrm{SD}=1.29544)$.

Table 4. Ranking of mean score for an organizational culture profile for studied hospitals $(n=250)$.

\begin{tabular}{|c|c|c|c|c|}
\hline \multirow[t]{2}{*}{ Competing value framework (CVF) } & \multicolumn{2}{|c|}{ Port Said General Hospital $(\mathrm{N}=150)$} & \multicolumn{2}{|c|}{ Hospital El Nasser $(\mathrm{N}=100)$} \\
\hline & MEAN & $\mathrm{SD}$ & Mean & SD \\
\hline CLAN & 3.3246 & .8505 & 3.7019 & 1.4635 \\
\hline ADHOC & 3.2090 & .77024 & 3.3991 & .96397 \\
\hline MARKET & 3.2512 & .77468 & 3.4742 & 1.3903 \\
\hline HIRARCH & 3.2979 & .80369 & 3.5977 & 1.2954 \\
\hline
\end{tabular}

Mean score of an organizational culture dimensions matches with competing value framework (CVF) in Port Said General Hospital presented in table 5. The findings revealed that highest mean score for management of employees; strategic emphasis and criteria of success at (mean= 3.3182 , $3.2727,3.2185,3.3660)$ respectivellty with Clan culture type which was reported as present culture type profile. Howover, the findings discovered that highest mean score was for leadership style and management glue with Hierarchy as second culture type as response of studied sample at (mean= $3.3289,3.5921$ ) On the other hand, only one higest mean score was for dominant an organizational characteristics with Market culture type at (mean=3.3484).

Table 5. Highest mean score on an organizational culture dimensions and competing value framework (CVF) in Port Said General Hospital as perceived by studied sample $(n=150)$.

\begin{tabular}{|c|c|c|c|c|}
\hline & \multirow{2}{*}{ Six organizational diminsions } & \multicolumn{3}{|c|}{ Port Said General Hospital (culture profile) $(\mathrm{N}=150)$. } \\
\hline & & Mean & SD & Culture type \\
\hline 1 & Dominant organizational characteristics & 3.3484 & .95750 & Market \\
\hline 2 & Leadership style & 3.3289 & .97503 & Hierarchy \\
\hline 3 & Management of employees & 3.2727 & 1.06195 & Clan \\
\hline 4 & Organizational glue & 3.5921 & .77468 & Hierarchy \\
\hline 5 & Strategic emphasis & 3.2185 & 1.02695 & Clan \\
\hline 6 & Criteria for success & 3.3660 & 1.10472 & Clan \\
\hline
\end{tabular}

Table 6 showed the highest mean score for organizational glue and management of employees at $($ mean $=3.5500,3.5000)$ respectively with Clan culture which was reported as culture profile. Also, the finding revealed that highest mean score was for leadership style and strategic emphasis with Hierarchy culture type as answered by studied sample at (mean=3.4487, 3.3924). While the only one highest mean score was recorded for criteria for success with Adhocracy type at (mean=3.5375) and dominant organizational characteristics for Market at (mean=3.3875).

Table 6. Mean score for competing value framework (CVF) in El- Nasser hospital by studied sample (n=100).

\begin{tabular}{|c|c|c|c|c|}
\hline \multirow{2}{*}{ Six Organizational dimisiosns } & \multicolumn{4}{|c|}{ Competing value framework (CVF) of El-Nasser Hospital $(n=100)$} \\
\hline & Clan & Adhocarcy & Market & Hierarchy \\
\hline Dominant organizational characteristics & 3.1500 & 3.2658 & 3.3875 & 3.3418 \\
\hline Leadership style & 3.5500 & 3.3974 & 3.1519 & 3.4487 \\
\hline Management of employees & 3.5000 & 3.1250 & 3.2875 & 3.2532 \\
\hline Organizational glue & 3.5500 & 3.3924 & 3.5190 & 3.6329 \\
\hline Strategic emphasis & 3.2375 & 3.2875 & 3.1375 & 3.3924 \\
\hline Criteria for success & 3.4625 & 3.5375 & 3.1899 & 3.4177 \\
\hline
\end{tabular}




\section{Discussion}

Anorganizational culture in a hospital setting is the product of shared values, attitudes and patterns of behavior which medical practitioners observe during the process of care delivery. Early research on culture focused on developing measures of culture or on empirically describing the culture of various organizational setting. Recent interest in the culture of healthcare organizations, however, has begun to address the importance of culture for key organizational outcomes (Rundall et al. 2002). When nurses and other medical practitioners are facilitated with a positive organizational culture, their commitment to a culture of error reporting and error sharing increases, consequently improving patient safety and reducing mortality rates (Jafree, R. S., Zakar, R, Zakar, Z. M., \& Fischer, F 2016). This research was done to find out the most dominant culture profile for each hospital by using the competing value framework (CVF). Total studied sample size was 250 participants, 150 from Port Said General Hospital and 100 from El-Nasser hospitals.

Generally, regarding organizational culture types, the care providers were ranked of culture type as the highest mean of an agreement was for Hierarchy organizational culture followed by Clan culture and as well as the lowest mean agreement was for the Adhocracy and Market organizational cultures. This finding supported by Seada (2012) found that the most dominant cultures were rational culture and hierarchal culture reported in governmental hospitals. Also, the findings pronounced that hospitals with rational and hierarchical cultures are less favorable to patient safety management whereas hospitals with the group (teamwork) and developmental culture are better aligned for patient safety management. Also, it goes with previous researches done by Zhang, Xia, and Pan, (2009) concluded that the managers, physicians, health technicians, nurses, and other employees in governmental hospitals in China have different functions and work under different environments, they may represent different subcultures within a hospital with different perceptions of the organizational culture. Furthermore, Hierarchy culture is an environment that places stress on formality, an integrated structure, formal regulations and policies, efficiency and stability. The management model of such a culture, which tends toward conformity, coordination, and seeks efficiency and smooth organizational operation, would find it easy to follow through and succeed in safety management (Chiu et al, 2008).

Summarized of an organizational culture profile for each hospital as perceived by studied sample. First, Port Said General Hospital, the care providers recorded Clan and Hierarchy culture as a culture profile in their hospital. Conversely, the lowest mean score was for an Adhocracy. Second, the findings revealed that Clan followed by Hierarchy culture were the first choice for them in El-Nasser hospital. Moreover, the lowest mean score was for Adhocracy. This result congruent with Kumaresan \&
Swarooprani (2016) found that the existence of mixed culture with a dominance of Clan and Hierarchy culture types as an overall culture profile of his study. According to Cameron and Quinn (2011), the most favorable cultures are Clan and Adhocracy to promote knowledge management while Market and Hierarchy actually inhibits it. However, it is not altogether unexpected that such results were found. These findings asserted by Singer,et.al., (2009) applied study aimed to explore how aspects of general organizational culture relate to hospital patient safety climate. It was found that there was a strong correlation between features of an organizational culture to safety climate. A higher level of safety climate-correlated with a higher level of group culture, but more hierarchical culture was associated with lower safety climate. Aspects of anorganizational culture accounted for more than threefold improvement in measures of model fit compared with models with controls alone. A mix of culture types, emphasizing group culture, appeared optimal for safety climate.

In Port Said General Hospital, The findings revealed that highest mean score for the management of employees; strategic emphasis and criteria of success with Clan culture type. Also, the findings spoke that highest mean score was for leadership style and management glue with Hierarchy as second culture type as a response of studied sample. On the other hand, only one highest mean score was for dominant organizational characteristics with Market. This result matches with Marziale, Carvalho, \& Campos (2014) analyzed of an organizational value of a public hospital, showed that nurses find the presence of hierarchical rigidity and the centralization of power in the organization (mean=3.22). For this reason, An Egypt governmental hospitals present autocratic organizational structures with the extreme centralization of decision making and excessive control of procedures, which leads to rigid management styles and protectiveness. There is an attachment to rules, routines and power of hierarchy, characteristics that hinder changing processes and that define organizational values and beliefs, as well as the human resources policy adopted by the organization (Schein, 2010).

The culture profile for El-Nasser hospital, the overall culture type was Clan which was reported by studied sample for organizational glue and management of employee, followed by the highest mean score was for leadership style and strategic emphasis on Hierarchy culture. The finding of this study going with Tsai (2011) showed that a correlation between leadership and organizational culture, consistent with the findings of our research. However, by adopting regression analysis, we also found that leadership behavior impacts on organizational culture. One highest mean score was recorded for criteria for success with an Adhocracy and dominant organizational characteristics for Market. These findings asserted by Kumaresan \& Swarooprani (2016) directors and managers have to understand the values of culture and take on board the effects of it while planning and decision making. Strategic planning has to be undertaken to 
identify the culture types of each decision have to be taken. Furthermore, An organizational culture is a driving force of that move people to action, act, and control organizational behavior and promote specific patterns of behavior (Sanjeev. Sharma and Aditi, 2010).

\section{Conclusion}

Based on the findings of this study, It concluded that the overall culture profile in both hospitals was Hierarchy organizational culture followed by Clan. While the lowest mean agreement was for the Adhocracy and Market organizational cultures. First hospital, the majority of studied sample reported agreement for Clan and Hierarchy culture profile in their current studied hospital. While this study also was asserted that one dimension profile demonstrated to be the lowest agreement from the overall, this is (Market) as an organizational culture. Equally, the second hospital (ElNasser), the most common culture profile was twodimensional profiles demonstrated to be different from the overall as Clan and Hierarchy culture. While the lowest mean agreement was for the Adhocracy and Market organizational culture. The findings of this study recommended that providing strategies that promote group orientation and reduced hierarchy, enhance the multidisciplinary team training and continuous quality improvement tools, and human resource practices and policies; permits to express ideas empower and encourage care providers to participate in decision-making and problem-solving process; conduct training workshop to learn and improve organizational culture in a manner that will increase the chances of financial and operational success; encourage continuous staff development programs for leaders and care providers to establish pride in their work and recognition by superiors which enhance organizational culture; conduct training workshop to learn and improve organizational culture in a manner that will increase the chances of financial and operational success and finally try to change a culture purely through top-down messaging, training and development programs, and identifiable signs seldom changes people's beliefs or behaviors.

\section{References}

[1] Aldhuwaihi, A. (2013). The influence of organizational culture on job satisfaction, organizational commitment and turnover intention: A study on the banking sector in the Kingdom of Saudi Arabia. Victoria University (Melbourne, Vic.).

[2] Alizadeh, S., \& Panahi, F. (2013). Organizational Culture Constructs in the Development of Organizational Trust. International Journal of Management Research and Review, 3 (8), 3238-3324.

[3] Balogh, A., Gaal, Z., \& Szabo, L. (2011). Relationship Between Organizational Culture and Cultural Intelligence. Management and Marketing Challenges for the Knowledge Society, 6 (1), 95-110.
[4] Cameron, K., \& Quinn, R. (2011). Diagnosing and changing organizational culture: Based on the competing values framework ( ${ }^{\text {ed }}$ Ed.). San Francisco, CA: Jossey-Bass.

[5] Chiu, C. H., Pan, W. H., and Wei, C. J, (2008): Dose organizational culture impact patient safety management. Asian Journal of Heath and Information Sciences, vol 3. N (1):, pp 88-100.

[6] Daft, R. L., Marcic, D. (2009). Management: The new workplace, South Western, International Student Edition.

[7] Domnariu, C., Cernuşcă-miţariu, M., \& Boitan, M. (2013). Organizational Culture - Important Factor In Delivering High Quality Health Care. Metalurgia International, 18 (8), 5-7.

[8] Jafree1, R. S., Zakar, R., Muhammad Zakria Zakar, Z. M., 3 \& Florian Fischer, F., (2016): Nurse perceptions of organizational culturand its association with the culture of error reporting: a case of public sector hospitals in Pakistan, BMC Health Services Research (2016) 16:3. DOI 10.1186/s12913-015-1252-y

[9] King, T., \& Byers, J. (2007). A Review of Organizational Culture Instruments for Nurse Executives. JONA: The Journal of Nursing Administration, 37 (1), 21-31.

[10] Kumaresan Chidambaranathan \& Swarooprani BS.(2015): Analyzing the relationship between organizational culture and knowledge management dimensions in higher education libraries, Journal of Librarianship and Information Science, sagepub.co.uk/journalsPermissions.nav DOI: 10.1177/0961000615622678.

[11] Marziale MHP, Carvalho MC, Id SFC, Campos MCT (2014): The organizational culture of a Brazilian public hospital Rocha FLR.

[12] Mitrovic, S., Grubic-Nesic, L., Milisavljevic, S., Melovic, B., \& Babinkova, Z. (2014). Manager's Assessment of Organizational Culture. E+M Ekonomik a Management, 17 (3), 35-49.

[13] Rundall, T., S. Shortell, M. C. Wang, L. Casalino, T. Bodenheimer, R. R. Gillies, J. A. Schmittdiel, N. Oswald, and J. C. Robinson. 2002. "As Good as It Gets? Chronic Care Management in Nine LeadingUS Physician Organizations." British Medical Journal 325 (7370): 958-64.

[14] Sanjeev K. Sharma and Aditi Sharma (2010): Examining the Relationship between Organisational Culture and Leadership Styles, Journal of the Indian Academy of Applied Psychology January 2010, Vol. 36, No. 1, 97-105.

[15] Schein EH. (2010): Organizational culture and leadership. 4th ed. San Francisco: Jossey-Bass.

[16] Seada M. A. (2012): Impact of Hospital Organizational Culture on Patient Safety Management from the Perspective of Nurses and Physicians in Selected Hospitals]Journal of American Science 2012; 8(X): X-X]. (ISSN:1545-1003).

[17] Shahzad, F., Luqman, R., Khan, A., \& Shabbir, L. (2012). Impact of Organizational Culture on Organizational Performance: An Overview. Interdisciplinary Journal of Contemporary Research in Business, 3 (9), 975-985. http://www.americanscience.org.

[18] Singer SJ, Falwell A, Gaba DM, Meterko M, Rosen A, Hartmann CW, Baker L. (2009): Health Care Manage Rev. 2009 Oct-Dec; 34 (4): 300-11. doi: 10.1097/HMR.0b013e3181afc10c. 
[19] Tsai, Y. (2011). Relationship between Organizational Culture, Leadership Behavior and Job Satisfaction. Health Services Research, 11 (98), 1-9.

[20] www.raosoft.com/samplesize.html.

[21] Yu. T. (2009). A Review of Study on the Competing Values Framework. International Journal of Business and Management, 7, 37-42.
[22] Zazzali, J. L., J. A. Alexander, S. M. Shortell, and L. R. Burns. 2007. "Organizational Culture and Physician Satisfaction with Dimensions of Group Practice." Health Services Research 42 (3): 1150-76.1152 HSR: Health Services Research 42:3, Part I ( June 2007).

[23] Zhang, Y. L., Xia. Li, and F. Pan. (2009): "The Relationship between Organizational Culture and Government Performance-Based on Denison Model." Asian Social Science 5 (11): 131-7. 